\title{
Pulmonary artery pressure during acute pulmonary oedema in patient with myocardial infarction
}

\author{
A. E. Tattersfield, ${ }^{1}$ M. W. McNicol, and R. W. Sillett \\ From Cardiothoracic Department, Central Middlesex Hospital, Park Royal, London
}

A patient with myocardial infarction was studied before, during, and after the development of acute pulmonary oedema. The haemodynamic measurements indicated poor left ventricular function before pulmonary oedema. Mean pulmonary artery pressure rose from 38 to $53 \mathrm{mmHg}$ during the acute episode and fell to 25 $\mathrm{mmHg}$ as clinical improvement occurred. The fall in pulmonary artery pressure was closely related in time to the administration of $3 \mathrm{mg}$ morphine intravenously.

Acute pulmonary oedema is a rapidly changing and unpredictable condition which is difficult to study in man. Occasionally haemodynamic measurements have been made when pulmonary oedema has occurred during cardiac catheterization, and these studies have shown a large rise in pulmonary artery pressure (Scebat, Lenegre, and Maurice, 1949; Finlayson et al., 1961 ; Yu, I969). Few measurements are available in patients with myocardial infarction and acute pulmonary oedema, and these were carried out several hours after the first signs of acute pulmonary oedema and after energetic treatment had been given. Nixon (1968) reported a patient with normal left atrial pressure and Knutsen and Broch (1968) found stroke index to be reduced in the 5 patients they studied but they did not measure left heart or pulmonary artery pressure.

During a recent study into the effects of intravenous diuretics in patients with myocardial infarction, one patient developed acute pulmonary oedema. This paper presents the clinical and haemodynamic findings before and during this episode and after treatment.

\section{Case report}

The patient, aged 64 , had experienced three episodes of chest pain between 1963 and 1968 ; these were diagnosed as myocardial infarction by his doctor and treated at home. The present admission followed 4 weeks of increasing angina and dyspnoea on exertion and was precipitated by severe chest pain lasting 20 minutes. The 1 Present address: The London Hospital, Whitechapel Road,
London EI IBB. electrocardiogram showed widespread recent anteroseptal infarction. On admission he had no pain and was slightly breathless but not distressed. He was in sinus rhythm ( 80 beats $/ \mathrm{min}$ ), blood pressure was $140 / 100$ $\mathrm{mmHg}$, the apex beat was in the 6th intercostal space, and heart sounds were normal. There were no signs of heart failure and no treatment was given. The following morning he was more dyspnoeic and had a sinus tachycardia ( 120 beats $/ \mathrm{min}$ ) and bilateral basal lung crepitations.

After obtaining informed consent from the patient a fine catheter (PE60) was floated into the pulmonary artery. Right atrial pressure was measured while the catheter was in the right atrium. A short cannula was inserted into the adjacent brachial artery. Pressures were measured using midthoracic point as reference zero. Cardiac output was measured by the dye dilution technique using indocyanine green. After a half-hour rest, baseline pressure measurements of cardiac output, and arterial blood gas tensions were made in duplicate over one hour with the patient breathing air. Frusemide $(80$ $\mathrm{mg}$ ) intravenously was then given and the same measurements were repeated $I$ and 2 hours later. The results are given in the Table. In the two hours after intravenous frusemide the patient passed $500 \mathrm{ml}$ urine. There was no change in his clinical condition.

Fifteen minutes after completion of the 2-hour measurements he developed rapidly increasing dyspnoea and orthopnoea with clinical signs of acute pulmonary oedema. He was given $0.25 \mathrm{mg}$ ouabain and $250 \mathrm{mg}$ aminophylline intravenously with very little benefit. Venous tourniquets were then applied to both legs. At this time it was possible to record pulmonary artery pressure which had risen from $37 \mathrm{mmHg}$ to $53 \mathrm{mmHg}$ (Fig.). Morphine (3 mg) was given slowly intravenously. Five minutes after the start of the injections the mean 
TABLE Haemodynamic and respiratory measurements: $80 \mathrm{mg}$ frusemide given at 12 a.m.; acute pulmonary oedema developed at 2.30 p.m.

\begin{tabular}{|c|c|c|c|c|c|c|}
\hline \multirow{3}{*}{$\begin{array}{l}\text { Time } \\
\text { Cardiac index }\left(1 . / \mathrm{min} \text { per } \mathrm{m}^{2}\right)\end{array}$} & \multirow{2}{*}{\multicolumn{2}{|c|}{$\frac{\text { Before frusemide }}{I I-I 2 \text { a.m. }}$}} & \multicolumn{4}{|c|}{ After frusemide } \\
\hline & & & \multirow{2}{*}{$\frac{I p . m .}{I \cdot 4}$} & \multirow{2}{*}{$\frac{2 p . m .}{1 \cdot 5}$} & \multirow[t]{2}{*}{2.30 p.m. } & \multirow[t]{2}{*}{6 p.m. } \\
\hline & $1 \cdot 3$ & $1 \cdot 45$ & & & & \\
\hline Stroke index $\left(\mathrm{ml} /\right.$ beat per $\left.\mathrm{m}^{2}\right)$ & II & 12 & 12 & 12 & & \\
\hline Heart rate (beats/min) & 125 & 120 & 120 & 128 & & \\
\hline Right atrial pressure (mmHg) & 8 & & & & & \\
\hline Pulmonary artery pressure (mmHg) & $50 / 32(38)$ & $48 / 32(38)$ & $45 / 31(35)$ & 47/35（37） & (53) & $38 / 25(29)$ \\
\hline Brachial artery pressure $(\mathrm{mmHg})$ & I I $/ 80(90)$ & I $12 / 76(88)$ & $120 / 85(95)$ & $107 / 77(90)$ & & \\
\hline Arterial oxygen tension $(\mathrm{mmHg})$ & 53 & 54 & 48 & 49 & & $5 \mathrm{I}$ \\
\hline Arterial carbon dioxide tension $(\mathrm{mmHg})$ & 32 & 32 & 30 & 32 & & 29 \\
\hline Arterial $p \mathrm{H}$ & $7 \cdot 49$ & $7 \cdot 50$ & $7 \cdot 50$ & $7 \cdot 52$ & & $7 \cdot 52$ \\
\hline
\end{tabular}

Figures in parentheses indicate mean pressures.

pulmonary artery pressure had fallen from 53 to 25 mmHg. Clinical improvement was then evident and continued with digitalis and further diuretic therapy. Mean pulmonary artery pressure 4 hours later was 29 $\mathrm{mmHg}$ and the following day was $31 \mathrm{mmHg}$. Gradual deterioration occurred however despite treatment, and he died 6 days after admission with intractable left ventricular failure. Serum potassium was normal throughout his illness.

Necropsy showed a large heart (430 g) with a large, recent anterior septal and lateral infarct, subendocardial infarction extending to the aortic valve, and an old fibrous inferior infarct. All the coronary arteries were grossly atheromatous, with 80 per cent narrowing and recent occlusive thrombosis of the left anterior descending coronary artery. The lungs were heavy (930 and $780 \mathrm{~g}$ ) and congested. There was a small right lower lobe pulmonary embolus with no definite lung infarction.

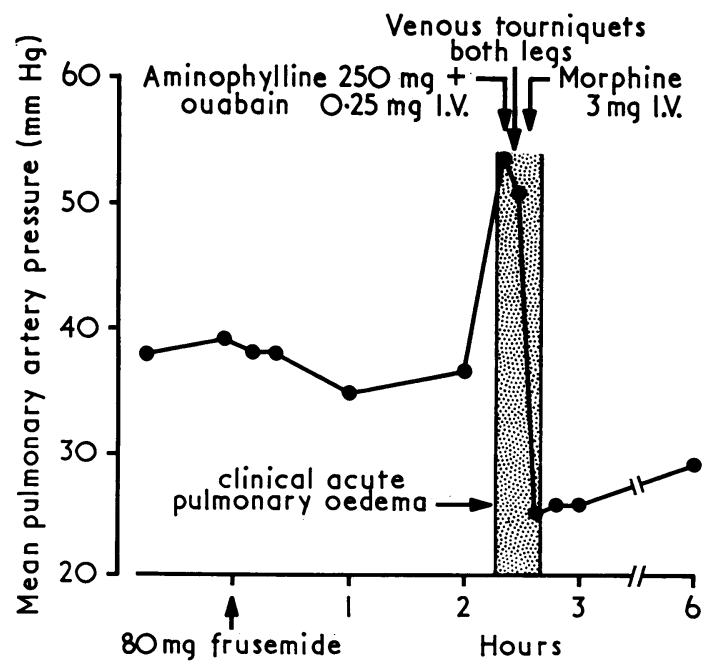

FIG. Changes in mean pulmonary artery pressure during acute pulmonary oedema.

\section{Discussion}

This patient demonstrates that a large gradient may occur between pressure in the right atrium and pulmonary artery in patients with myocardial infarction. Right atrial pressure was only $8 \mathrm{mmHg}$ and, clinically, jugular venous pressure was not raised before the onset of pulmonary oedema despite the pronounced raised pulmonary artery pressure of $50 / 32 \mathrm{mmHg}$. Though we have found a significant correlation between right atrial and pulmonary artery pressure in myocardial infarction (Tattersfield, McNicol, and Sillett, 1972), normal central venous pressure does not exclude severe pulmonary hypertension.

During the acute episode of pulmonary oedema there was a rise in mean pulmonary artery pressure from 37 to $53 \mathrm{mmHg}$. The maximum rise was probably greater as the latter measurement was made approximately io minutes after the development of acute pulmonary oedema and after the administration of ouabain and aminophylline and the application of tourniquets. This finding is similar to those observed in patients with rheumatic heart disease during acute pulmonary oedema where the most distinctive feature has been the pronounced rise in both pulmonary artery pressure and pulmonary wedge or left atrial pressure (Scebat et al., 1949; Finlayson et al., 196I ; Yu, 1969).

There is now much evidence to show that the raised pulmonary artery pressure in myocardial infarction is primarily reflecting increased left ventricular enddiastolic pressure (Kirby, McNicol, and Tattersfield, I968; Hodges et al., 1969; Russell et al., 1970; Rahimtoola et al., 1972). The high pulmonary artery pressure and very low stroke index in this patient indicates extremely poor left ventricular function before the onset of acute pulmonary 
oedema. In patients with such poor left ventricular function, it has been shown that changes in filling pressure are associated with little or no change in stroke index (Russell et al., 1970; A. E. Tattersfield, M. W. McNicol, and R. W. Sillett, unpublished observations. Further increases in filling pressure will eventually be associated with a fall in stroke volume (Ross et al., 1966). This is an inherently unstable situation in which left ventricular filling pressure will rise rapidly. We believe that our patient reached this situation which caused the very rapidly developing pulmonary oedema.

In this patient the factors precipitating acute pulmonary oedema are not known. In vulnerable patients with poor left ventricular function a small increase in venous return or in peripheral vascular resistance or slight further impairment of left ventricular function could precipitate pulmonary oedema. Changes in venous return and peripheral vascular resistance occur with such everyday activities as changing posture or micturition (Marshall and Shepherd, I968). It is unlikely that the diuretic was related to the development of pulmonary oedema as diuretics usually produce a fall in pulmonary artery pressure (Sjögren, I970; Tattersfield et al., unpublished observations). None of the other 34 patients in the same study developed pulmonary oedema.

It is impossible to say categorically which therapeutic measure, if indeed any, contributed to the rapid reduction in pulmonary artery pressure. There was very little clinical improvement following ouabain, aminophylline, and the venous tourniquets, and the close time relation with intravenous morphine suggests that morphine was probably mainly responsible. This is consistent with observations on the pulmonary circulation in man (Roy et al., 1965; $\mathrm{Yu}, 1969)$ and on the peripheral circulation in animals (Henney et al., I966), which suggest that morphine causes a redistribution of blood toward the peripheral circulation. It may be judicious to give intravenous morphine with caution in this situation so that the reduction in filling pressure is not excessive.

The Medical Research Council supported the authors and the laboratory in which the measurements were made.

\section{References}

Finlayson, J. K., Luria, M. N., Stanfield, C. A., and Yu, P. N. (1961). Hemodynamic studies in acute pulmonary edema. Annals of Internal Medicine, 54, 244.

Henney, R. P., Vasko, J. S., Brawley, R. K., Oldham, H. N., and Morrow, A. G. (1966). The effects of morphine on the resistance and capacitance vessels of the peripheral circulation. American Heart fournal, 72, 242.

Hodges, M., Friesinger, G. C., Riggins, R. C. K., and Dagenais, G. R. (1969). Effects of digoxin on early left ventricular failure in acute myocardial infarction (abstract). Circulation, 40, Suppl. 3, 107.

Kirby, B. J., McNicol, M. W., and Tattersfield, A. E. (1968). Left ventricular pressures in two patients with myocardial infarction. Lancet, $1,944$.

Knutsen, B., and Broch, O. J. (1968). Haemodynamics in acute pulmonary oedema in coronary patients. Acta Medica Scandinavica, 183, 531 .

Marshall, R. J., and Shepherd, J. T. (1968). Cardiac Function in Health and Disease. W. B. Saunders, Philadelphia and London.

Nixon, P. G. F. (1968). Pulmonary oedema with low left ventricular diastolic pressure in acute myocardial infarction. Lancet, 2, 146.

Rahimtoola, S. H., Loeb, H. S., Ehsani, A., Sinno, M. Z., Chuquimia, R., Lal, R., Rosen, K. M., and Gunnar, R. M. (1972). Relationship of pulmonary artery to left ventricular diastolic pressures in acute myocardial infarction. Circulation, 46, 283

Ross, J., Gault, J. H., Mason, D. T., Linhart, J. W., and Braunwald, E. (1966). Left ventricular performance during muscular exercise in patients with and without cardiac dysfunction. Circulation, 34, 597.

Roy, S. B., Singh, I., Bhatia, M. L., and Khanna, P. K. (1965). Effect of morphine on pulmonary blood volume in convalescents from high altitude pulmonary oedema. British Heart fournal, 27, 876.

Russell, R. O., Rackley, C. E., Pobmboramos, J. F., Hunt, D. U., Potanin, C., and Dodge, H. T. (1970). Effects of increasing left ventricular filling pressure in patients with acute myocardial infarction. American fournal of Cardiology, 25, 125.

Scebat, L., Lenegre, J., and Maurice, P. (1949). La pression sanguine dans la petite circulation au cours de cinq crises accidentelles d'oedème pulmonaire aigu mineur. Bulletin et Mémoires de la Société Médicale des Hopitaux de Paris, 65, 134 .

Sjögren, A. (1970). Left heart failure in acute myocardial infarction. Acta Medica Scandinavica, Suppl. 5 IO.

Tattersfield, A. E., McNicol, M. W., and Sillett, R. W. (1972). Relationship between haemodynamic and respiratory function in patients with myocardial infarction and left ventricular failure. Clinical Science, 42, $75 \mathrm{I}$

Yu, P. N. (1969). Pulmonary Blood Volume in Health and Disease. Lea and Febiger, Philadelphia.

Requests for reprints to Dr. A. E. Tattersfield, The London Hospital, Whitechapel, London EI IBB. 